\title{
Performance Analysis of a Southern Mediterranean Seaport via Discrete-Event Simulation
}

\author{
Francesco Longo $1{ }^{1}{ }^{*}$ - Aida Huerta ${ }^{2}$ - Letizia Nicoletti ${ }^{1}$ \\ 1 University of Calabria, Department of Mechanical, Energetic and Management Engineering, Italy \\ 2 National University of Mexico, Department of Systems Engineering, Mexico
}

\begin{abstract}
Modeling \& Simulation (M\&S) has proved to be a day-to-day highly indispensable tool for complex systems design, management and monitoring. Therefore, the proposed research study aims to develop a simulation model to recreate the complexity of a medium-sized Mediterranean seaport and analyse the performance evolution of such system with particular reference to the ship turnaround time. After the input data analysis, simulation model development, verification and validation, a design of experiments (according to a 24 factorial experimental design) was carried out in order to evaluate how some critical factors (i.e. inter-arrival times, loading/unloading times, number of cars and trucks to be unloaded/loaded) may affect the seaport's performance. To this end an analysis of variance is performed and an analytical input-output meta-model was created to evaluate the system's performance.
\end{abstract}

Keywords: logistics, marine ports, supply chain, modeling \& simulation

\section{INTRODUCTION}

Despite the economic and financial crisis, statistics show that merchant fleets are growing: more than 138,000 seagoing commercial ships are currently in service [1]. These data prove the crucial role of seaports for both national and international trade. In this framework, the Mediterranean Sea represents one of the most strategic areas with $15 \%$ of global shipping activities taking place at mainly western and central Mediterranean ports [2]. Therefore decision making in seaports requires the support of powerful tools allowing performance measurement and analysis. To this end, the main goal of this research work is to propose a simulation-based tool of a mediumsize Mediterranean seaport that could be used by the main port administrators (i.e. port managers, the port authority, etc.) to support decision making and process management. Indeed, all port stakeholders need to monitor their performance taking into account quantitative and qualitative aspects, determining whether their strategies produce the desired outcomes, and correcting any misallocations and malfunctions [3].

Performance measurements can be considered in terms of three kinds of indicators: key result indicators (KRIs), performance indicators (PIs), and key performance indicators (KPIs) [4]. As reported in [3], port performance measurements - usually recommended to the port community stakeholders - are divided into five categories: market trends and structure; socio-economic impact; environmental performance; logistic chains; and operational performance and governance. In such a context, modeling and simulation $(M \& S)$ has proved to be a valuable methodology for performance assessment, as well as enhancement and monitoring activities in complex systems. Indeed its first applications in industry and logistics dates back to 1980 [5] to [7]. Among others, discrete-event simulation (DES) is a leading simulation paradigm used to study operational and planning processes within domains like industry [8], logistics and supply chains and more specifically within seaports. In effect, DES is able to capture and recreate the highly dynamic evolutionary processes that are typical of complex real systems. A simulation model of an inland port can be found in [9], whereas [10] and [11] propose simulation models devoted to evaluating logistical and operational processes in marine terminals. Considering the port terminal capacity, [12] and [13] propose simulation models to investigate the capacity increment that can be achieved through new management strategies applied to the devices and equipment available, while avoiding additional capital costs. With reference to security issues in marine ports, namely inspection procedures within container terminals, it has been proved that simulation can be an effective tool for supporting decision, which can be easily integrated into the day-to-day container terminal operations [14] and [15]. Furthermore, in this field, simulation has been successfully applied in conjunction with artificial intelligence techniques for systems performance optimization [16] to [19]. Although it has been proven that $M \& S$ is able to support seaport management at various levels (even when combined with agent based approaches [20] such as multiagent systems [21] or when the simulation model is designed to reproduce the microscopic, stochastic, real-time environment of a part of the container 
terminal i.e. a multiple-berth facility [22]), it is also important to consider that decision-making processes imply different planning horizons. To this end, [23] this study develops different microscopic DES models for a container terminal, focusing on the best approach to simulate container handling activities and their time duration. In addition, it is worth mentioning that when applied to marine ports M\&S is also a very powerful methodology for supporting advanced and cooperative training, exercise and education [24] and [25].

The above brief state of the art overview shows that $M \& S$ can provide valuable support within seaports. Therefore the main aim of this research work is to develop an advanced simulation model able to recreate the main processes and activities of a medium size Mediterranean seaport in order to analyse the evolution of the turnaround time of certain types of ships (i.e. Roll-on Roll-off, Ro-Ro ships) when the ships inter arrival time, the duration of the loading/ unloading activities and the number of cars and trucks loaded/unloaded change. The paper is structured as follows: Section 1 presents the simulation methodology, Section 2 describes the simulation model development, Section 3 deals with the validation of the simulation model, Sections 4 and 5 propose the design of experiments and the simulation results analysis, while the last section summarizes the conclusions.

\section{SIMULATION METHODOLOGY}

As stated before, DES is one of the most common simulation paradigms used to investigate real complex systems. Through DES, in fact, it is possible to model the system behaviour over time as a series of events that change the system status [25]. Therefore the methodological approach applied in this research work relies on M\&S fundamentals in order to explore the operating procedures in a seaport, as well as to obtain a greater understanding and to analyse their performance evolution over the time. To this end, the key processes of this simulation study comply with the approach well-established in the literature (see [26] to [29]):

- objectives and overall project plan setting;

- model conceptualization;

- data collection and input data analysis;

- $\quad$ simulation model development);

- simulation model validation and optimal run length;

- design of experiments;

- simulation results analysis.

\subsection{Port Conceptual Model}

It is widely recognized that conceptual models are used to document those aspects of a real system that need to be represented in computerized models as well as the ones that need to be omitted. The system studied in this research work is a medium-sized Mediterranean seaport (the port of Salerno) with a strategic logistic position in the middle of the Mediterranean sea and a primary role in trade exchanges involving southern Italy. Its strategic position led us to consider this seaport as one of the main Italian ports of call for the 'motorways of the Sea' that are part of the transEuropean transport network (TEN-T) and Marco Polo II program. In this study, the commercial seaport has been considered as a system where seven physical zones are distinguished: the West Pier, the Red Quay, the Trapezio Pier, the Ligea Quay, the 3 January Pier, the Manfredi Pier, and the Levanter Pier; the layout of the seaport is shown in Fig. 1. The seaport offers regular Ro-Ro and passengers (RoRo/Pax) connections to the ports of Valencia, Malta, Tunis, Messina, Palermo, Tripoli, Termini Imerese, and Cagliari. The Ro-Ro/Pax macro-activities, the container handling operations, ferry and merchandise operations have been included in the conceptual model. Some of the activities' conceptual flows are depicted in Figs. 2 and 3. After arrival the ship waits outside the port until a berth position becomes available; mooring operations are in many cases performed with the help of tugboats (above all for large vessels that cannot use the side thrusters close to the berth). After unloading/loading operations the vessels leave the port. It is important to outline that due to the physical size of the seaport, ships can only enter or exit the seaport one by one. In addition, exit has priority over entry.

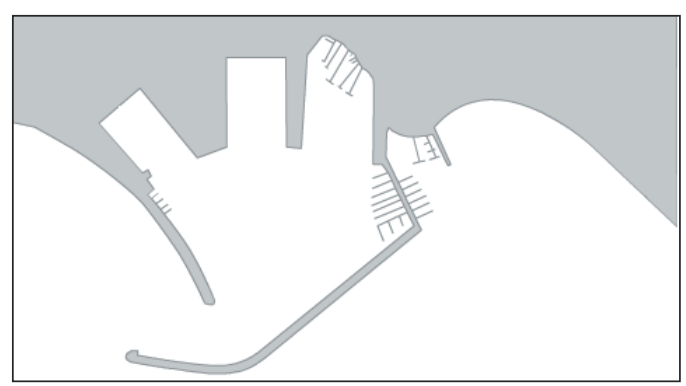

Fig. 1. Seaport layout

\subsection{Data Collection and Input Data Analysis}

Data collection plays a crucial role in simulation studies and affects the development and use of 


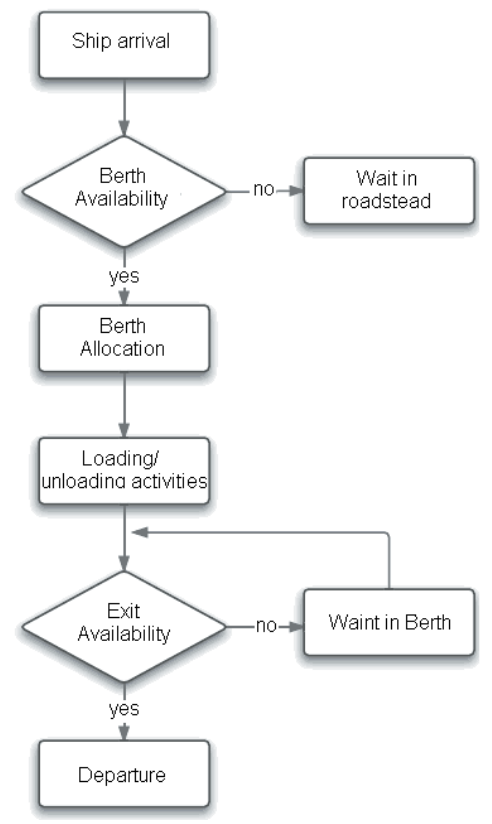

Fig. 2. Flow chart of the arrival/departure process

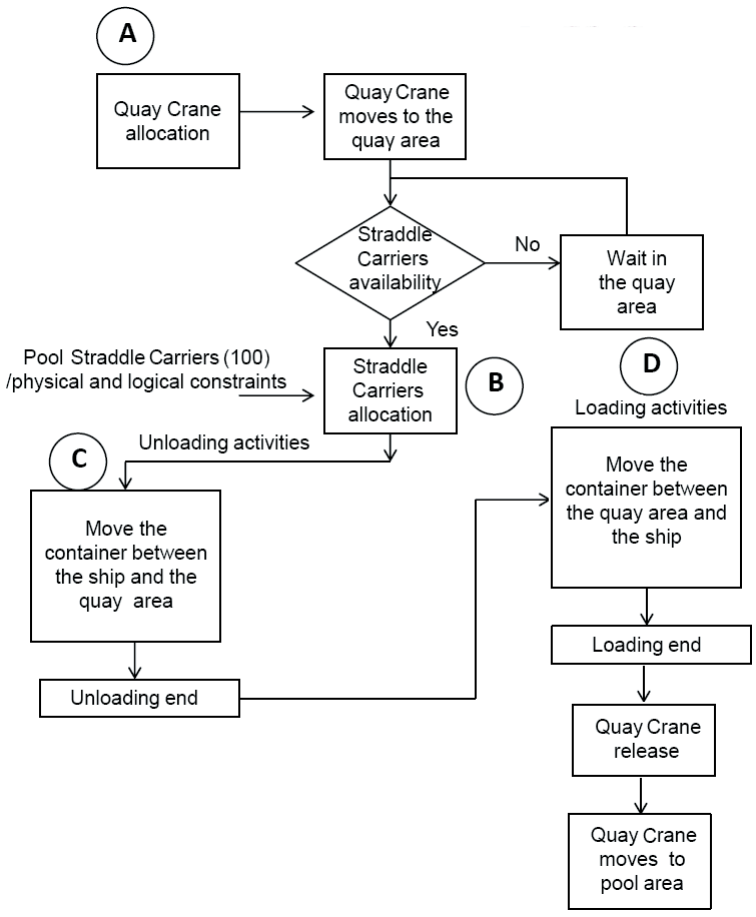

Fig. 3. Flow chart of the quay crane allocation process

simulation models. The accuracy of the simulation is affected by the quality of the input data, which is why special attention should be paid to this step. In effect, if the data used to design and populate the model are inaccurate, the results of the model will be inaccurate as well.
It is worth stating that the random behaviour of some variables makes a seaport a stochastic system. As reported in [26], for each element in a system being modelled, the simulation analyst must decide on a way to represent the associated variables. The data collection step takes care of collecting data for all port processes and activities as well as finding the most suitable computer representation for such data. Usually there are three different choices: (i) data are deterministic or data are considered to be deterministic, (ii) a distribution probability is fitted to the empirical data and (iii) the empirical distribution of the data is directly used in the simulation model [30] to [31]. In our case the second and the third choices have been used.

For the purposes of this study, data on actual ship arrivals from January, 1st, 2010 to December, 31st, 2011 and from January 1th, 2012 to May 14th, 2012 were collected and used in the simulation model. In the case of stochastic variables and distribution fitting, the procedure for input data analysis is the classical procedure proposed by many statistics handbooks as well as implemented in numerous commercial software applications: (i) starting from a histogram of the data, one or more candidate distributions are hypothesized, (ii) for each distribution the characterizing parameters are estimated, (iii) a goodness of fit test is performed, and (iv) lastly, the best distribution is chosen. For any additional information on input data analysis for simulation studies please refer to [26] and [33]. The $K$ intervals for each input parameter of the model were obtained taking into consideration equal-width intervals and using Scotts' formula [32] (see Eq. (1)).

$$
K=1.15 \mathrm{~N}^{1 / 3}, \mathrm{~N} \geq 25 \text {. }
$$

Then, the $\mathrm{N}$ data collected were fitted into the probability density functions based on the $K$ intervals. As an example, the simulation input values for the RoRo/Pax ships is presented in Fig. 4.

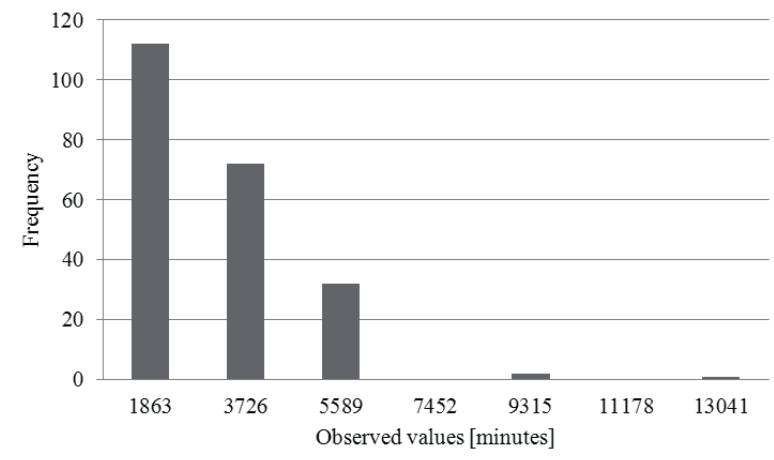

Fig. 4. Interarrival time of Ro-Ro/Pax ships 


\section{SIMULATION MODEL DEVELOPMENT}

The translation of the conceptual model into a computerized model is one of the key steps in a simulation study. In this research work the simulation model was implemented using the Anylogic ${ }^{\circledR}$ (6.4) simulation software. It is a Java-based and general purpose simulation tool that takes advantage of the power of Java in any part of the model or in any library. These features make Anylogic ${ }^{\circledR}$ a suitable tool for simulating complex systems such as seaports. Furthermore it allows the simulation of various domains using different approaches, and also provides animation, which can be useful in supporting the decision-making processes of seaport planners. The authors have extensive experience in developing simulation models in the field of supply chains [34] as well as in seaports and container terminals [14]. Therefore the approach used for the development of the simulation model proposed in this paper follows the same logics and rules already used in other research works by the same authors. For the sake of clarity a description of the port simulation model development is reported in the remaining part of this section (according to the same structure used in [14]).
The container terminal simulation model is in four parts: (i) the flow chart that recreates the main port activities; (ii) the transportation networks that allows the recreation of entities and resources movements within the port area; (iii) the graphic user interface and output section for scenarios definition and performance measures monitoring, respectively; (iv) the animation main frame recreating a $2 \mathrm{D}$ animation of all the port operations including vessel arrivals and departures, as well as vessel unloading and loading operations. Basically, at the beginning of the flow chart there are different source objects used to generate different types of vessels. Each vessel is then re-directed into one of the flow chart branches according to the type of vessel and berth position. In each branch the following operations are simulated: mooring operations, unloading and loading operations, and detachment operations according to the resources available. Finally after unloading and loading operations, vessel detachment operations are performed and the vessel can leave the port area. As part of the flow chart, the terminal resources used for executing the operations described above are of three different types: autonomous resources (i.e. forklift, quay cranes, tugboat, trucks etc.), support resources

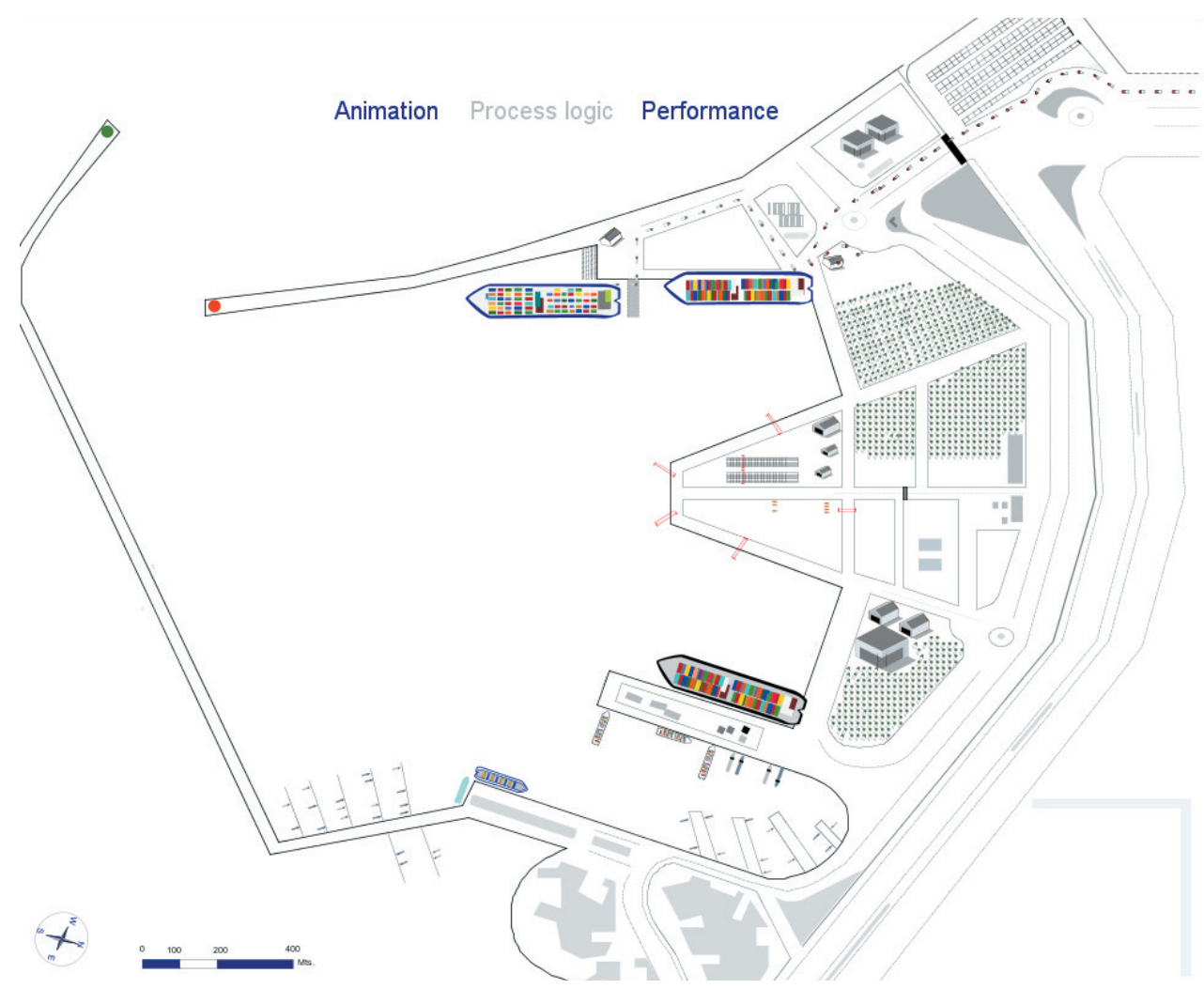

Fig. 5. Simulation model animation 
(i.e. a chassis for a truck, a spreader for a forklift, etc.), or static resources (i.e. a quay crane position, a parking position, etc.).

Transportation networks (built on the port layout) are used to handle entities and resources movements while simultaneously defining the animation main frame of the simulation model. In effect, defining these networks requires inserting class objects both into the simulation model flow chart and into the simulation model animation. Within the simulation model flow chart, a network is made up of several objects that allow entry into the network, taking resources from the network, moving within the network, freeing the resources, and exiting the network. For example, consider the case of a forklift that is supposed to move a container from the quay crane area to the yard area. The container enters the network, takes the resource forklift, waits until the resource forklift becomes available (then the forklift performs the movement from the quay crane area to the yard area), frees the resource forklift, and, if needed, leaves the network.

Within the simulation model animation a network is made up of rectangles and lines (respectively, resource locations and trajectories between locations). A rectangle represents a network entry or exit point, the idle position for some resource, or a destination point in the port. A line is the path followed by an entity moving among rectangles. For example, consider again the case of the container to be moved from the quay crane area to the yard area. During the animation, the container appears in a rectangle located in the quay crane area, it waits there until the forklift becomes available and then the forklift moves the container to the yard area by following the path specified by the lines connecting the quay crane area rectangles and the yard area rectangles. Fig. 5 shows the final animation of the simulation model based on the transportation network.

In order to develop an advanced interactive tool for testing scenarios, the most important variables, analysis and problems solving, are defined as parameters; each parameter has specific range values and statistical distribution forms and its values can be changed by using a dedicated graphic user interface. Similarly a dedicated output section shows the results of the simulations, i.e. the simulation model including information (for each vessel type) about the actual port traffic, the number of ships as a function of the arrival time, the empirical distributions (as histograms) for the average waiting time for a berth position, the average waiting time for mooring operations, the average service time, and the average turn-around time.

\section{SIMULATION MODEL VALIDATION AND OPTIMAL RUN LENGTH}

The simulation model validation aims at establishing whether the simulation model is providing valid and reliable outputs (close to the real system outputs). In addition, a seaport is a non-terminating system; this implies that the duration of a simulation run is not a-priori fixed therefore the optimal length of a simulation run has to be defined. For this purpose a mean square pure error analysis (MSpE) was applied. The MSpE is a characteristic of the simulation model; it is related to the overall stochasticity of the real system that is represented within the simulation model [35]. The MSpE allows the simulation run length to be chosen because it is an unbiased estimator of the error affecting the simulation model results. One should note that the MSpE is an intrinsic characteristic of the simulation model, therefore in this case it has been evaluated in relation to the service time of the ships arriving at the seaport. This simulation output has been analysed based on confidence intervals rather than point estimators, thus providing a realistic analytical framework (a confidence interval with a confidence level of $99.75 \%$ has been calculated for the service time but also for an additional performance measure, the number of ships per week). The MSpE evolution for the Ro-Ro/Pax ships arriving at the seaport is a suitable knee curve, as illustrated in Fig. 6 and the values for the confidence intervals (in terms of the lower confidence limit (LCL) and the upper confidence limit (UCL)) are summarized in Table 1. After a simulation time of 60 weeks, the value of the MSpE was quite small. At that time, the effect of the noise produced by a casual overlapping of the probability density functions related to the input parameters on the simulation results was minimized considerably. In addition, the comparisons between the real values and the confidence intervals calculated by the simulation model suggest that the simulation model is able to recreate the real system with satisfactory accuracy. Under these circumstances the DES model can be considered a valid support for decision-making processes.

Table 1. Confidence interval (99.75\%)

\begin{tabular}{lcc}
\hline Ro-Ro/Pax ships & Real value & $\begin{array}{c}\text { Simulated confidence interval } \\
{[\mathrm{LCL}, \mathrm{UCL}]}\end{array}$ \\
\hline Ships per week & 3.46 & {$[3.32,4.30]$} \\
\hline Service time $[\mathrm{h}]$ & 7.42 & {$[6.58,7.47]$} \\
\hline
\end{tabular}




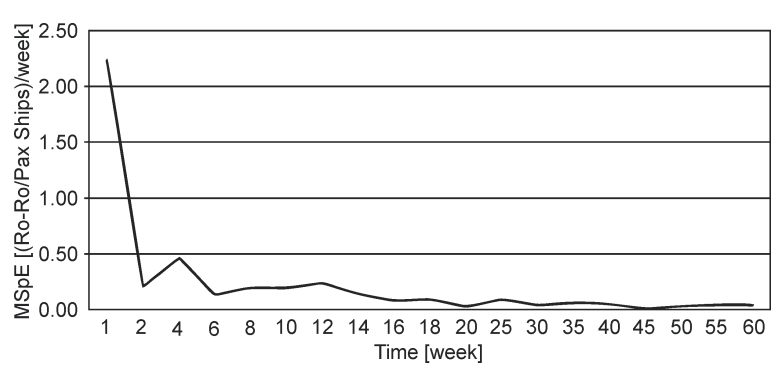

Fig. 6. MSpE analysis (Ro-Ro passenger ships per week)

\section{DESIGN OF EXPERIMENTS}

The design of experiments was used to plan and execute the simulation runs. In particular, a $2^{4}$ factorial experimental design was chosen to analyse the evolution of Ro-Ro/Pax turnaround time given some input parameter changes. The $2^{4}$ factorial experimental design implies that 16 simulation runs are needed to study 4 factors (input parameters) each one having two different levels (a minimum and maximum level). In other words, the simulation runs are made for all the possible factor level combinations. Factorial experimental designs are particularly useful in the early stages of an experimental work [33] to select or screen out the few important main effects from the less important ones.

Each simulation run of 60 weeks' length has been replicated 5 times. The input parameters and their two levels are presented in Table 2.

Table 2. Parameters for the $2^{4}$ experiments design

\begin{tabular}{lccc}
\hline \multicolumn{1}{c}{ Factor } & Var. & Level [-1] & Level [1] \\
\hline Inter-arrival time of ships [h] & $x_{1}$ & 42 & 60 \\
\hline $\begin{array}{l}\text { Unloading/Loading time of } \\
\text { Ro-Ro /Pax [min] }\end{array}$ & $x_{2}$ & 0.5 & 1.5 \\
\hline Numbers of cars & $x_{3}$ & 50 & 100 \\
\hline Numbers of trucks & $x_{4}$ & 50 & 100 \\
\hline
\end{tabular}

As only two levels for each input factor were taken into consideration, only a linear regression can be carried out to express the response as a function of the input factors. The simulation results have been analysed using the Minitab ${ }^{\circledR}$ software taking into account the influence of the inter-arrival time of the ships, the loading/unloading time of Ro-Ro/Pax and the number of cars and trucks over the turnaround time. For the levels of the inter-arrival times please refer to the empirical distributions shown in Figs. 7 and 8 .

In other words, Figs. 7 and 8 represent two histograms that are $20 \%$ lower and $20 \%$ greater than the real empirical distribution of the inter-arrival times, respectively.

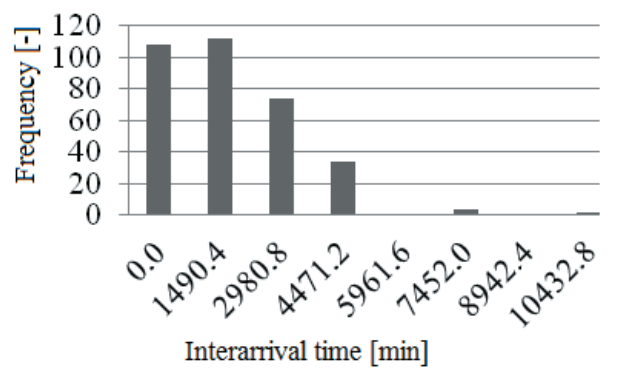

Fig. 7. Inter arrival time of Ro-Ro/Pax ships (20\% lower than the real empirical distribution of the inter-arrival times)

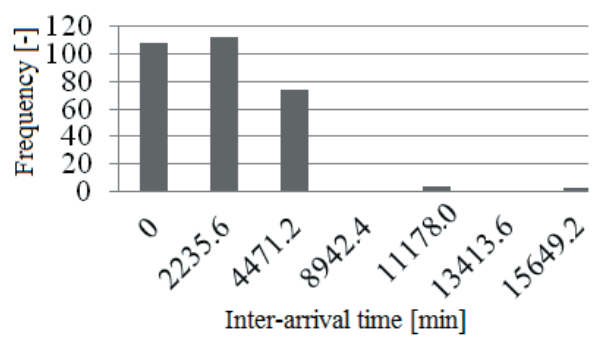

Fig. 8. Inter arrival time of Ro-Ro/Pax ships (20\% greater than the real empirical distribution of the inter-arrival times)

\section{SIMULATION RESULTS ANALYSIS}

Since two levels of each input factor have been taken into account, it is interesting to compare how changes in these levels impact the turnaround time using an analysis of variance (ANOVA). The ANOVA partitions the total variability of the turnaround time into different components due to the influence of the change in the inter-arrival time, the Ro-Ro/Pax unloading/loading time, the number of cars and the numbers of trucks.

Table 3 and Fig. 9 present the ANOVA results obtained using the Minitab ${ }^{\circledR}$ software. The column DF indicates the degrees of freedom of each input parameter. The adjusted mean squares is a statistical indicator that allows the total variability for each factor to be evaluated. Column $\mathrm{P}$ is the probability of accepting as true the hypothesis that a factor has no impact on the response considered (shown here for turnaround time: in other words the column P pertains to the probability of error in accepting the alternative hypothesis that a factor has no impact on the response considered). The ANOVA results show that the factors taken into account as well as their interactions significantly affect the turnaround time and therefore cannot be neglected. 


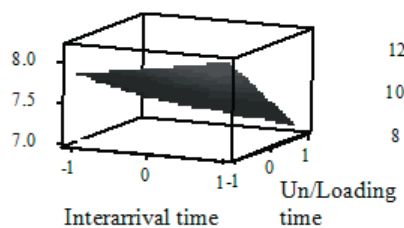

Interarrival time time

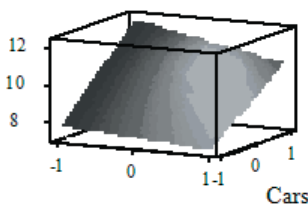

Un/Loading time
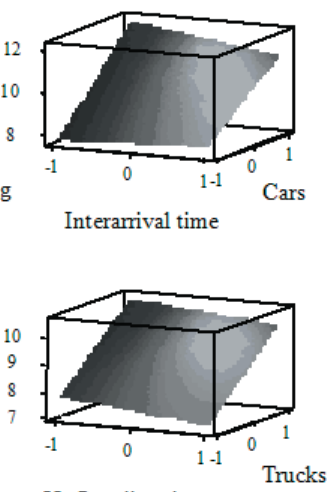

Un/Loading time

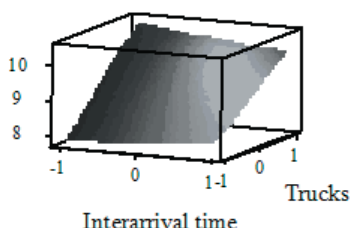

Interarrival time

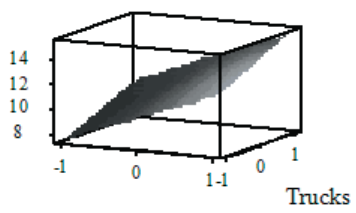

Cars

Fig. 9. Input factors versus output

Table 3. Analysis of variance for the turnaround time

\begin{tabular}{cccc}
\hline Source & $\begin{array}{c}\text { Degrees of } \\
\text { Freedom (DF) }\end{array}$ & $\begin{array}{c}\text { Adjusted Mean } \\
\text { Squares (Adj MS) }\end{array}$ & $P$ \\
\hline$x_{1}, x_{2}, x_{3}, x_{4}$ & 4 & 0.42 & 0.00 \\
\hline $\begin{array}{c}x_{1} x_{2}, x_{1} x_{3}, x_{1} x_{4}, \\
x_{2} x_{3}, x_{2} x_{4}, x_{3} x_{4}\end{array}$ & 6 & 8.25 & 0.00 \\
\hline $\begin{array}{c}x_{1} x_{2} x_{3}, x_{2} x_{3} x_{4}, \\
x_{1} x_{3} x_{4}, x_{1} x_{3} x_{4}\end{array}$ & 4 & 8.78 & 0.00 \\
\hline$x_{1} x_{2} x_{3} x_{4}$ & 1 & 2.83 & 0.00 \\
\hline Total & 15 & & \\
\hline
\end{tabular}

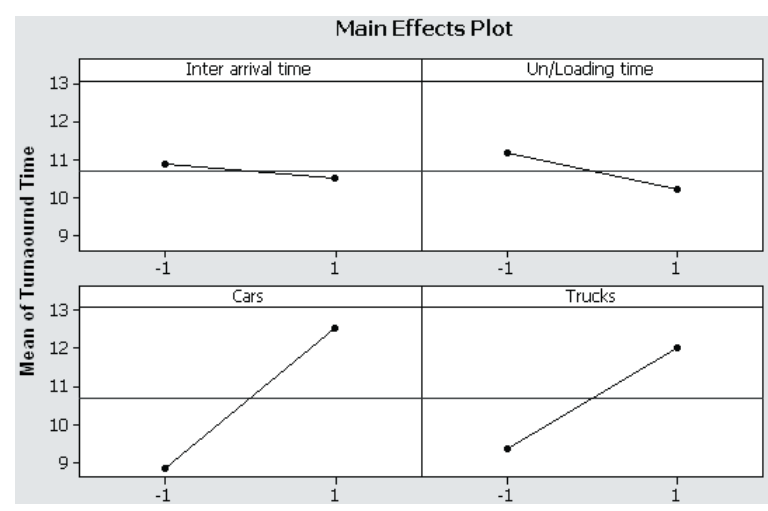

Fig. 10. Analysis of variance for the turn-round time

Based on the ANOVA results, shown graphically in Fig. 10, and on the mean value of the turnaround time ( 8.42 hours), it is possible to conclude that:

- if the inter-arrival time increases, the turnaround time of the ship Ro-Ro/Pax will decrease from 11 to 10.5 hours;

- if the number of cars unloaded/loaded increases from 50 to 100 , the turnaround time will increase from 8.8 to 12.5 hours, while increasing the number of trucks unloaded/loaded from 50 to
100 , the turnaround time increases from 9.5 to 12 hours;

- and, if the unloading/loading time of the cars and of the trucks increases from 0.5 to 1.5 minutes, the turnaround time will decrease from 11 to 10 hours.

ANOVA allows us to evaluate a meta-model of the simulation model that expresses the response as an analytical function of the factors considered. Consequently, the general form of the linear model that relates the turn-around time $(Y)$ to the four input factors $\left(x_{1}, x_{2}, x_{3}, x_{4}\right)$ is expressed by Eq. (2).

$$
\begin{aligned}
Y= & \sum_{j=1}^{j=4} \beta_{j} x_{j}+\sum_{i=1}^{i=3} \sum_{j=i+1}^{j=4} \beta_{i j} x_{i} x_{j}+ \\
& +\sum_{i=1}^{i=2} \sum_{j=i+1}^{j=3} \sum_{k=j+1}^{k=4} \beta_{i j k} x_{i} x_{j} x_{k}+ \\
& \sum_{i=1}^{i=1} \sum_{j=i+1}^{j=2} \sum_{k=j+1}^{k=3} \sum_{n=k+1}^{n=4} \beta_{i j k n} x_{i} x_{j} x_{k} x_{n}+\varepsilon .
\end{aligned}
$$

Table 4 reports the main effects and interaction effects (up to order 4) as well as the coefficents of Eq. (2). The main effects and interaction effects express the variation in the average turnaround time when the factors change from their minimum levels to their maximum levels.

From Table 4 we can observe that the three largest effects on the turnaround time are the interactions between $x_{1} x_{3}, x_{2} x_{3}, x_{1} x_{2} x_{3}$, that correspond to the interactions between inter-arrival time and the number of cars, unloading/loading time and the number of cars, inter-arrival time, unloading/loading time and number of cars, respectively. In addition, Table 4 shows the $\beta_{i}$ and $\beta_{i j}$ coefficient to be inserted in Eq. (2). Therefore, by using such coefficients the 
analytical meta-model can be expressed in explicit form (see Eq. (3)).

Table 4. Residuals from the $2^{4}$ design

\begin{tabular}{ccc}
\hline Source & Effect & Coefficient \\
\hline Constant & & 10.70 \\
\hline$x_{1}$ & 0.12 & 0.06 \\
\hline$x_{2}$ & 0.49 & 0.24 \\
\hline$x_{3}$ & -0.24 & -0.12 \\
\hline$x_{4}$ & -0.34 & -0.17 \\
\hline$x_{1} x_{2}$ & -1.35 & -0.68 \\
\hline$x_{1} x_{3}$ & 2.49 & 1.25 \\
\hline$x_{1} x_{4}$ & 0.79 & 0.39 \\
\hline$x_{2} x_{3}$ & 1.41 & 0.70 \\
\hline$x_{2} x_{4}$ & 0.92 & 0.46 \\
\hline$x_{3} x_{4}$ & -0.94 & -0.47 \\
\hline$x_{1} x_{2} x_{3}$ & 2.04 & 1.02 \\
\hline$x_{1} x_{2} x_{4}$ & -1.93 & -0.97 \\
\hline$x_{1} x_{3} x_{4}$ & -0.44 & -0.22 \\
\hline$x_{2} x_{3} x_{4}$ & -0.82 & -0.41 \\
\hline$x_{1} x_{2} x_{3} x_{4}$ & 0.84 & 0.42 \\
\hline
\end{tabular}

$$
\begin{aligned}
\hat{Y} & =0.06 x_{1}+0.24 x_{2}-0.12 x_{3}-0.17 x_{4}- \\
& -0.68 x_{1} x_{2}+1.25 x_{1} x_{3}+0.39 x_{1} x_{4}+ \\
& +0.70 x_{2} x_{3}+0.46 x_{2} x_{4}-0.47 x_{3} x_{4}+ \\
& +1.02 x_{1} x_{2} x_{3}-0.97 x_{1} x_{2} x_{4}-0.22 x_{1} x_{3} x_{4}- \\
& -0.41 x_{2} x_{3} x_{4}+0.42 x_{1} x_{2} x_{3} x_{4}+10.70
\end{aligned}
$$

Eq. (3) can be seen as an additional outcome of the simulation model; indeed the estimated values that have been used to build this metamodel are the simulation outputs. It can be used (apart from the simulation model) for evaluating the port performance (in terms of vessel turn-around time) depending on the values of some well-established critical factors. Therefore it is a decision support tool that port managers can use to understand seaport behaviour or to investigate different operative scenarios when the factors under consideration change. It is worth pointing out that the analysis proposed above is only an example of an application in order to highlight the simulation model potential as a tool for supporting the port manager's decision making process. In fact, the simulation model can be used to carry out additonal analysis considering multiple performance measures (i.e. average time spent by all the ships in the port areas, container handling equipment efficiency, etc.) and all those input factors that may have an inpact on the port's performance.

\section{CONCLUSIONS}

The developed DES model allows the macro activities carried out in a Mediterrenean seaport to be explored. The reliability of the simulation model was ensured by applying the MSpE technique for validation purposes. The validation process was a crucial step in the simulation study and was indispensable for considering the seaport DES model as a valid support tool for decisions-making. Preliminary simulation experiments were carried out following a 24 factorial experimental design and the simulation outputs were investigated by applying the ANOVA. This methodology has clearly shown that inter-arrival time, Ro-Ro/Pax unloading/loading time, number of cars, and number of trucks are crucial factors for seaport performance in terms of turnaround time. In addition, an analytical meta-model relating the turn-around time to the input factors was evaluated. The meta-model is an additional tool that can be used apart from (or even jointly with) the simulation model to investigate how the input factors affect the seaport's behaviour.

\section{REFERENCES}

[1] UNCTAD (2012). Merchant fleet by flag of registration and by type of ship, annual, 1980-2012, from http:// unctadstat.unctad.org/TableViewer/tableView. aspx? ReportId =93, accessed on 2013-01-08.

[2] Lloyd's Marine Intelligence Unit (2008). Study of maritime traffic flows in the Mediterranean Sea. Final Report - Unrestricted Version of the European Union financed MEDA regional project "Euromed co-operation on Maritime Safety and Prevention of Pollution from Ships - SAFEMED", from http://80.33.141.76/esatdor/attachments/article/69/ Maritime_Traffic_Flows.pdf accessed on 2013-01-08.

[3] ESPO (European Sea Ports Organisation). (2012). Port Performance Indicators Selection and Measurements. Project executive Report, from http://pprism.espo.be/LinkClick.aspx?fileticket $=$ sv7LYCzIJs\%3D\&tabid=3555, accessed on 2013-0108.

[4] Parmenter, D. (2007). Key Performance Indicators, Developing, Implementing, and Using Winning KPIs, $2^{\text {nd }}$ ed., John Wiley and Sons, New Jersey.

[5] Bruzzone, A.G., Longo, F. (2010). An advanced system for supporting the decision process within large-scale retail stores. Simulation, vol. 86, no. 12, p. 742-762, DOI:10.1177/0037549709348801.

[6] Woo, S.H., Pettit, S.J., Kwak, D.W. (2011). Seaport research, a structured literature review on methodological issues since the 1980s. Transportation Research Part A, vol. 45, no. 7, p. 667-685, DOI:10.1016/j.tra.2011.04.014. 
[7] Cortés, P., Munuzuri, J., Ibanez, J.N., Guadix, J. (2007). Simulation of freight traffic in the Seville inland port. Simulation Modelling Practice and Theory, vol. 15, no. 3, p. 256-271, DOI:10.1016/j.simpat.2006.11.004.

[8] Yazdani, R., Schmidt, F.A., Merkuryev, Y., Kamperman, F. (2005). The generic animation and simulation tool for ports and terminals. International Journal of Simulation Systems, Science \& Technology, vol. 6, no. 7-8. p. 61-69.

[9] Bugaric, U., Petrovic, D. (2007). Increasing the capacity of terminal for bulk cargo unloading. Simulation Modelling Practice and Theory, vol. 15, no. 10 p. 1366-1381, DOI:10.1016/j.simpat.2007.09.006.

[10] Parola, F., Sciomachen, A. (2009). Modal split evaluation of a maritime container terminal. Maritime Economics \& Logistics, vol. 11, no. 1, p. 77-97, DOI:10.1057/mel.2008.22.

[11] Bruzzone, A., Longo, F., Nicoletti, L., Bottani, E., Montanari, R. (2012). Simulation, analysis and optimization of container terminals processes. International Journal of Modeling, Simulation, and Scientific Computing, vol. 3, no. 4, art. 1240006, DOI:10.1142/S1793962312400065.

[12] Bruzzone, A., Signorile, R. (1998). Simulation and genetic algorithms for ship planning and shipyard layout. Simulation, vol. 71, no. 2, p. 74-83, DOI:10.1177/003754979807100202.

[13] Bruzzone, A. (2004). Preface to modeling and simulation methodologies for logistics and manufacturing optimization. Simulation, vol. 80 , no. 3 p. 119-120, DOI:10.1177/0037549704045812.

[14] Bruzzone, A., Fancello, G., Fadda, P., Bocca, E., D'Errico, G., Massei, M. (2010). Virtual world and biometrics as strongholds for the development of innovative port interoperable simulators for supporting both training and R\&D. International Journal of Simulation and Process Modeling, vol. 6, no. 1, p. 89102, DOI:10.1504/IJSPM.2010.032661.

[15] Garro, A., Russo, W. (2010). easyABMS: a domainexpert oriented methodology for agent based modeling and simulation. Simulation, Modeling Practice and Theory, vol. 18, no. 10 p. 1453-1467, DOI:10.1016/j. simpat.2010.04.004.
[16] Douma, A.M., Van Hillegersberg, J., Schuur, P.C. (2012). Design and evaluation of a simulation game to introduce a multi-agent system for barge handling in a seaport. Decision Support Systems, vol. 53, no. 3 p. 465-472, DOI:10.1016/j.dss.2012.02.013.

[17] Petering, E. (2010). Development and simulation analysis of real-time, dual-load yard truck control systems for seaport container transshipment terminals. OR Spectrum, vol. 32, no. 3 , p. 633-661, DOI:10.1007/ s00291-009-0183-6.

[18] Cartenì, A., de Luca, S. (2012). Tactical and strategic planning for a container terminal: Modelling issues within a discrete event simulation approach. Simulation Modelling Practice and Theory, vol. 21, no. 1, p. 123 145, DOI:10.1016/j.simpat.2011.10.005.

[19] Bruzzone, A.G., Longo, F. (2012). 3D simulation as training tool in container terminals: The TRAINPORTS simulator. Journal of Manufacturing Systems, vol. 32, no. 1, p. 85-98, DOI:10.1016/j.jmsy.2012.07.016.

[20] Bruzzone, A.G., Fadda, P., Fancello, G., Massei, M., Bocca, E., Tremori, A., Tarone, F., D’Errico, G. (2011). Logistics node simulator as an enabler for supply chain development: innovative portainer simulator as the assessment tool for human factors in port cranes. Simulation, vol. 87, no. 10, p. 857-874, DOI:10.1177/0037549711418688.

[21] Banks, J. (1998). Handbook of Simulation. J. Wiley and Sons, New York, DOI:10.1002/9780470172445.

[22] Shannon, R.E. (1975). Systems Simulation: The Art and Science. Prentice-Hall, New Jersey.

[23] Gordon, G. (1978). System Simulation, 2nd ed. PrenticeHall, New Jersey.

[24] Law, A.M., Kelton, W.D. (2006). Simulation Modeling and Analysis, 4th ed., McGraw-Hill, New York.

[25] Scott, D.W. (1979). On optimal and data-based histograms. Biometrika, vol. 66, no. 3 , p. 605-610, DOI:10.1093/biomet/66.3.605.

[26] Montgomery, D.C. (2002). Applied Statistics and Probability for Engineers, $3^{\text {rd }}$ ed. John Wiley and Sons, New York.

[27] Mee, R.W. (2009). A Comprehensive Guide to Factorial Two-Level Experimentation. Springer-Verlag, New York, DOI:10.1007/b105081. 